\title{
ESTIMATION OF CONDITION OF CULTIVATED PASTURES UNDER REMOTE SENSING OF EARTH
}

\author{
Vladimir Trukhachev ${ }^{1}$, Serhii Oliinyk ${ }^{1}$, Ilya Mikhailenko ${ }^{2}$, Valeriy Timoshin ${ }^{2}$, Tatyana Lesnyak ${ }^{1}$ \\ ${ }^{1}$ Stavropol State Agrarian University, Russia; ${ }^{2}$ Agrophysical Research Institute, St. Petersburg, Russia \\ rector@stgau.ru, soliynik60@gmail.com, ilya.mihailenko@yandex.ru, timoshinv@yandex.ru, \\ tatastav026@gmail.com
}

\begin{abstract}
To maintain the quality and productivity of cultivated pastures, it is necessary to make various kinds of management decisions in a timely manner. These include alternation of pens, timing of the mowing of grass stands, application of fertilizers, etc. These decisions should be made based on reliable information about the current state of pastures, which should be assessed according to information from automated monitoring systems. Considering the large areas, to generate reliable information on the state of pastures, it is extremely important to use for these purposes means of remote sensing of the Earth (RSD) of various basing (satellite, aviation, surface). This paper presents a methodology for estimating the state parameters of pasture grass stands based on the integration of remote sensing data and ground-based measurements on test plots. Such integration is implemented in the optimal filtering algorithm, built based on mathematical models of the dynamics of the parameters of the state of herbage and optical measurements of remote sensing. To identify and quickly adapt the models, samples of plants and soil are taken from the test pasture sites. To estimate the spatial in homogeneity of the state parameters of the grass stands, the models were transformed for two-dimensional state variables and methods for obtaining estimates of grazing land were shown. For the development of spatial distribution of estimates, mathematical models were added with bidimensional variable numbers. Different approaches were suggested for their evaluations according to the images of electronic remote sensing. The results of evaluation can be used for making managing solutions, which are directed to keep the quality and the productivity of the pasture plant formation.
\end{abstract}

Keywords: estimation, biomass, cultivated pastures, remote sensing, mathematical models.

\section{Introduction}

Effective interaction of pasture and livestock is possible only when rationing grazing and evaluating the possible pasture production. By dividing pasture into pens, it is possible to regulate livestock grazing as part of the pasture rotation. This allows annually one of the pens to exclude from grazing and put it on rest [1;2]. In the years of rest it is advisable to fertilize and mow the grass at a late date, so that seeds can crumble in the sod. After that, they are put into the soil by harrowing and other methods, not excluding easy grazing, thereby renewing the herbage. Practice shows that the alternation of early, middle, and late haying is optimal for meadows, and therefore, farms organize haying, where the time for mowing of different sections alternates. This allows maintaining high species diversity and productivity of meadows and pastures.It is reliably known that the application of nitrogen fertilizers most strongly affects the composition and productivity of the herbage. Fertilization also plays the role of a smoothing factor, reducing fluctuations over the years of the yield and botanical composition of the community. Pasture productivity is guaranteed even in adverse weather conditions [2].

The given characteristic of pastures indicates that in order to maintain their quality and productivity, and to exclude pasture digression, accompanied by a drop in productivity and replacement of steppe grass with weeds, it is necessary to make various kinds of management decisions. These include alternation of pens, timing of the mowing of grass stands, application of fertilizers, etc. These decisions should be made on the basis of reliable information about the current state of pastures, which should be assessed according to information from automated monitoring systems. Given the large areas, for the formation of reliable information on the state of pastures, means of remote sensing of the Earth (Earth remote sensing) of various basing (satellite, aviation, surface) are extremely important.

Currently requirements have been formed for a set of indicators for monitoring the pasture condition:

- $\quad$ species composition, reserves and structure of phytomass;

- projective cover;

- presence of litter (steppe felt) and its thickness; 
- soil codification;

- soil density;

- structural state of the soil (maintenance of agronomically valuable aggregates and their water resistance);

- content, reserves and composition of humus;

- content of nutrients (N, P, K);

- thickness of the humus horizon;

- presence of linear erosion forms and their sizes.

From the above list of modern optical means of Earth remote sensing it is possible to evaluate the indicators directly related to the parameters of phytomass of pasture grass stands and using radar tools (radar) to assess the parameters of the soil environment.

The purpose of this work is to substantiate the methodology for assessing the state of the phytomass of pasture grass stands according to remote sensing data (Earth remote sensing).

\section{Materials and methods}

Requirements of accuracy, reliability of high performance monitoring systems are due to the need to use information from remote sensing systems to make various kinds of control decisions. At the same time, the information obtained in these systems is only indirectly related to the productive indicators of crops and the physical indicators of the root-inhabited environment. This leads to large errors in determining the state of crops and soil. To reduce estimation errors, it is proposed to use the theory of filtering in stochastic systems [3]. This theory is aimed at significantly improving the accuracy of assessing the state of crops and the soil environment, taking into account their spatial distribution and heterogeneity. In accordance with this methodology, a significant increase in accuracy is achieved through the development of dynamic models of production indicators of crops and the physical condition of the soil environment. Simultaneous use of a priori information from dynamic models and operational information from remote sensing means allows optimizing the entire assessment process in terms of accuracy. At the same time, this optimization is achieved simultaneously through two channels of information - direct compensation of measurement errors and reduction of modeling errors [4;5-9]. The mathematical models included in this methodology are as follows:

- phytomass state parameters $[7 ; 10 ; 11]$

$$
\begin{aligned}
{\left[\begin{array}{l}
\dot{x}_{1} \\
\dot{x}_{2}
\end{array}\right]=\left[\begin{array}{ll}
a_{11} & a_{12} \\
a_{21} & a_{22}
\end{array}\right]\left[\begin{array}{l}
x(t)_{1 m} \\
x(t)_{2 m}
\end{array}\right]+\left[\begin{array}{lll}
c_{11} & c_{12} & c_{13} \\
c_{21} & c_{22} & c_{23}
\end{array}\right]\left[\begin{array}{l}
f_{1}(t) \\
f_{2}(t) \\
f_{3}(t)
\end{array}\right]+\left[\begin{array}{ll}
b_{11} & b_{12} \\
b_{21} & b_{22}
\end{array}\right]\left[\begin{array}{l}
u_{1}(t) \\
u_{2}(t)
\end{array}\right]+\left[\begin{array}{l}
\zeta_{1}(t) \\
\zeta_{2}(t)
\end{array}\right], t \in(0, T), } \\
{\left[\begin{array}{l}
x_{1}(0) \\
x_{2}(0)
\end{array}\right]=\left[\begin{array}{lll}
d_{11} & d_{12} & d_{13} \\
0 & 0 & 0
\end{array}\right]\left[\begin{array}{l}
w_{1}(0) \\
w_{2}(0) \\
w_{3}(0)
\end{array}\right], }
\end{aligned}
$$

- optical measurement model (ERS) [6;12]

$$
\begin{gathered}
y_{1}(t)=p_{1} e^{-p_{2}\left(x_{1}(t)+x_{2}(t)\right)}+\varepsilon_{1}(t), \\
y_{2}(t)=p_{3} e^{-p_{4} x_{2}(t)}+\varepsilon_{2}(t) ;
\end{gathered}
$$

where $x_{1}, x_{2}-$ dry and wet above-ground mass of plants, $\mathrm{kg}$ in a given area;

$f_{1}$ - average daily air temperature, ${ }^{\circ} \mathrm{C}$;

$f_{2}$ - average daily radiation level, $\mathrm{W} \cdot\left(\mathrm{m}^{2} \text { hour }\right)^{-1}$;

$f_{3}$ - average daily precipitation, $\mathrm{mm}$;

$t$ - time, days. 
Perturbations of the initial conditions in the model (1) are:

$w_{1}-$ content of available nitrogen in the soil, $\mathrm{g} \cdot \mathrm{kg}^{-1}$;

$w_{2}$ - content of available potassium, $\mathrm{g} \cdot \mathrm{kg}^{-1}$;

$w_{3}-$ content of available phosphorus, $\mathrm{g} \cdot \mathrm{kg}^{-1}$.

Control factors in the model (1) are:

$u_{1}-$ content of available nitrogen in the soil, $\mathrm{g} \cdot \mathrm{kg}^{-1}$;

$u_{2}$ - soil moisture content, \%;

$a_{11}-a_{22}, c_{11}-c_{23}, b_{11}-b_{22}, d_{11}-d_{13}-$ model parameters;

$\zeta_{1}(t), \zeta_{2}(t)$ - random noise in the model, having zero mean and variances $d_{1}, d_{2}$;

$y_{1}(t)$ - optical reflection index obtained from the first measurement channel (in the video band);

$y_{2}(t)$ - optical indicator, reflections, obtained by the second measurement channel (in the infrared range);

$p_{1}-p_{4}$ - parameters of the optical measurement system, estimated from experimental data; $\varepsilon_{1}(t), \varepsilon_{2}(t)$ - random noise in the probe meter model, having zero mean and variance $\sigma_{1}^{2}$, $\sigma_{2}^{2}$.

Models (1), (2) can be represented in symbolic vector-matrix form.

$$
\begin{gathered}
\bar{X}=A X+C F(t)+B U(t), \\
X(0)=D_{1} W(0), \\
Y_{x}=F(X)+E(t), \\
F(X)=\left[\begin{array}{l}
p 1 e^{-p_{2}}\left(x_{1}(t)+x_{2}(t)\right) \\
p_{3} e^{-p_{4} x_{2}}(t)
\end{array}\right], \\
X(0)=X_{0}, \\
M[E(t)]=0, \operatorname{cov}[E(t)]=S, \\
M[\zeta(t)]=0, \operatorname{cov}[\zeta(t)]=D,
\end{gathered}
$$

where $A, C, B$ - matrices of model parameters corresponding to the expanded form of the model $(1)$

$X$ - vector of biomass state parameters,

$Y_{X}-$ vector of reflection parameters of the ERS system;

$F(X)$ - vector function of the model of optical measurements, the vector of random modeling errors, having a covariance matrix $\mathrm{D}$, the vector of errors of optical measurements, having a covariance matrix

$S, M$ - mathematical expectation operation.

The presence of models (1), (2) allows simultaneous use of a priori information about the measured state, generated by the dynamic model, and a posteriori information of the meters (ERS), which makes it possible to compensate for errors of both sources of information. The algorithm of integration of these models, which is the final results of the above methodology, has the following form [3-5;9]:

$$
\begin{gathered}
\hat{\dot{X}}=A \hat{X}+C F(t)+R(t) \frac{F^{T}(\hat{X})}{X} S^{-1}\left(Y_{x}(t)-F(\hat{X})\right), \\
\dot{R}=D+R(t) A^{T}+A R(t)-R(t) \frac{F^{T}(\hat{X})}{X} S^{-1} \frac{F(\hat{X})}{X} R(t)
\end{gathered}
$$




$$
\begin{gathered}
t \in(0, T), \hat{X}(O)=M\left[X_{0}\right], R(0)=\operatorname{cov}\left[X_{0}\right] \\
S=\left[\begin{array}{ll}
S_{1}^{2} & S_{1} S_{2} \\
S_{1} S_{2} & S_{2}^{2}
\end{array}\right],
\end{gathered}
$$

where $\hat{\dot{X}}$ - assessment of the state of biomass of perennial grasses by field area, obtained from remote sensing data;

$\frac{\partial F(\hat{X})}{\partial \hat{X}}$ - partial derivative of the measurement model for the vector of biomass state parameters;

$R$ - field-average covariance matrix of the vector of estimates;

$T-$ transpose index of the vector or matrix.

A significant problem in the general problem of estimation is identification of the mathematical models used, namely, the dynamic model of the parameters of the state of sowing of pasture grass stand and the model of optical sounding [13;14]. The essence of this problem lies in the fact that the herbage and soil environment have non-stationary and time-varying properties, which in turn leads to changes in the parameters of the mathematical models used. The neglect of such changes can lead to the appearance of large errors in estimating the parameters of the phytomass of the herbage and making inadequate decisions. To solve this problem, it is proposed to use the methodology of test plots, when 10-12 contiguous plots with an area of $25-30 \mathrm{~m}^{2}$ each are allocated to pasture (preferably at one of the available edges). At each site a different combination of doses of NPK mineral fertilizers is applied and the soil is moistened with different irrigation norms. Such differences lead to differences in the parameters of the state of grass on these sites. Then, periodically every three days, samples are taken of plants and soil, which form the database of parameters of the state of sowing and the soil environment in accordance with the mathematical models (1), (2). The number of such measurements must be at least 10. Using the database generated in this way, the parameters are evaluated (identified) for the models (1), (2).

\section{Discussion of the results}

Fig. 1 presents a graph of such identification of the model of parameters of the state of the stand (1), and Fig. 2 presents the graph of identification of the model of optical measurements (2).

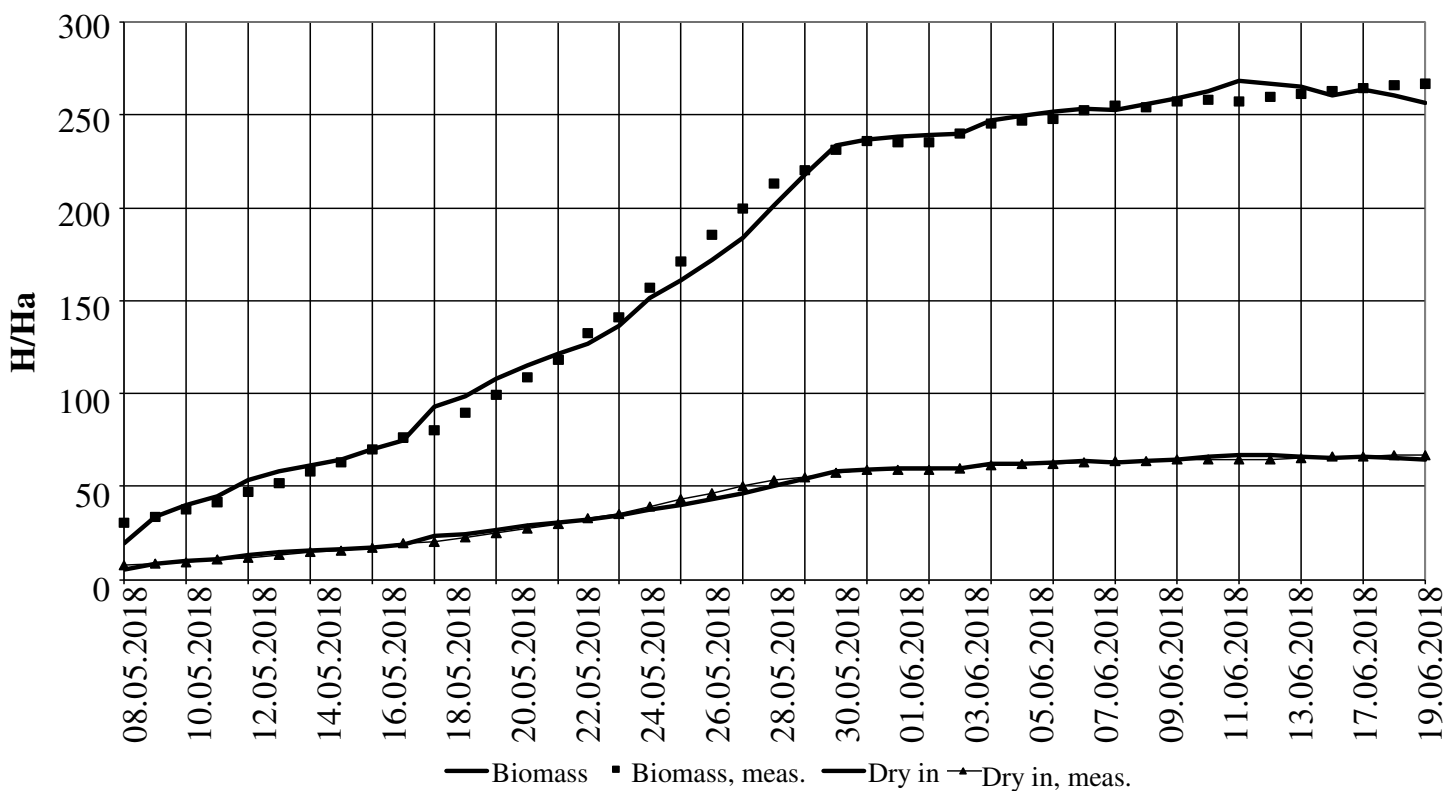

Fig. 1. Process of identifying model of parameters of state of sowing perennial grasses at one of periods between individual mowings by date 


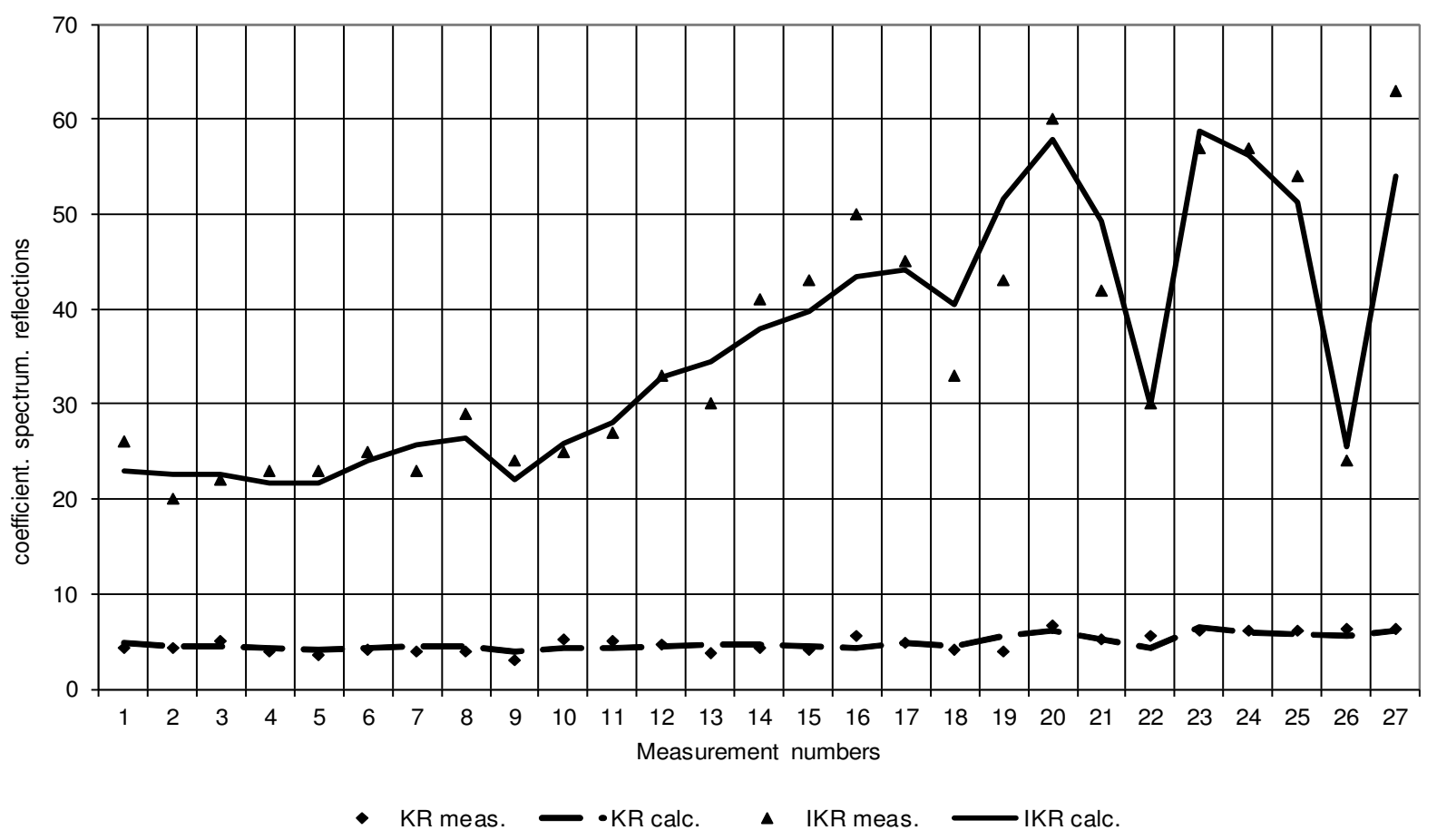

Fig. 2. Process of identifying model of optical meter system for remote sensing system

On both graphs the geometric figures show the experimental points, and the solid lines show the trajectories of the model settings. In Fig. 2, along the horizontal axis, various options for combining the biomass parameters of the herbage stand. The vertical axis represents the reflection parameters in the red (RED) and infrared (IRED) regions of the spectrum.

Fig. 3 presents the process of estimating the biomass parameters of the grass stand according to the Earth Remote Sensing Data.

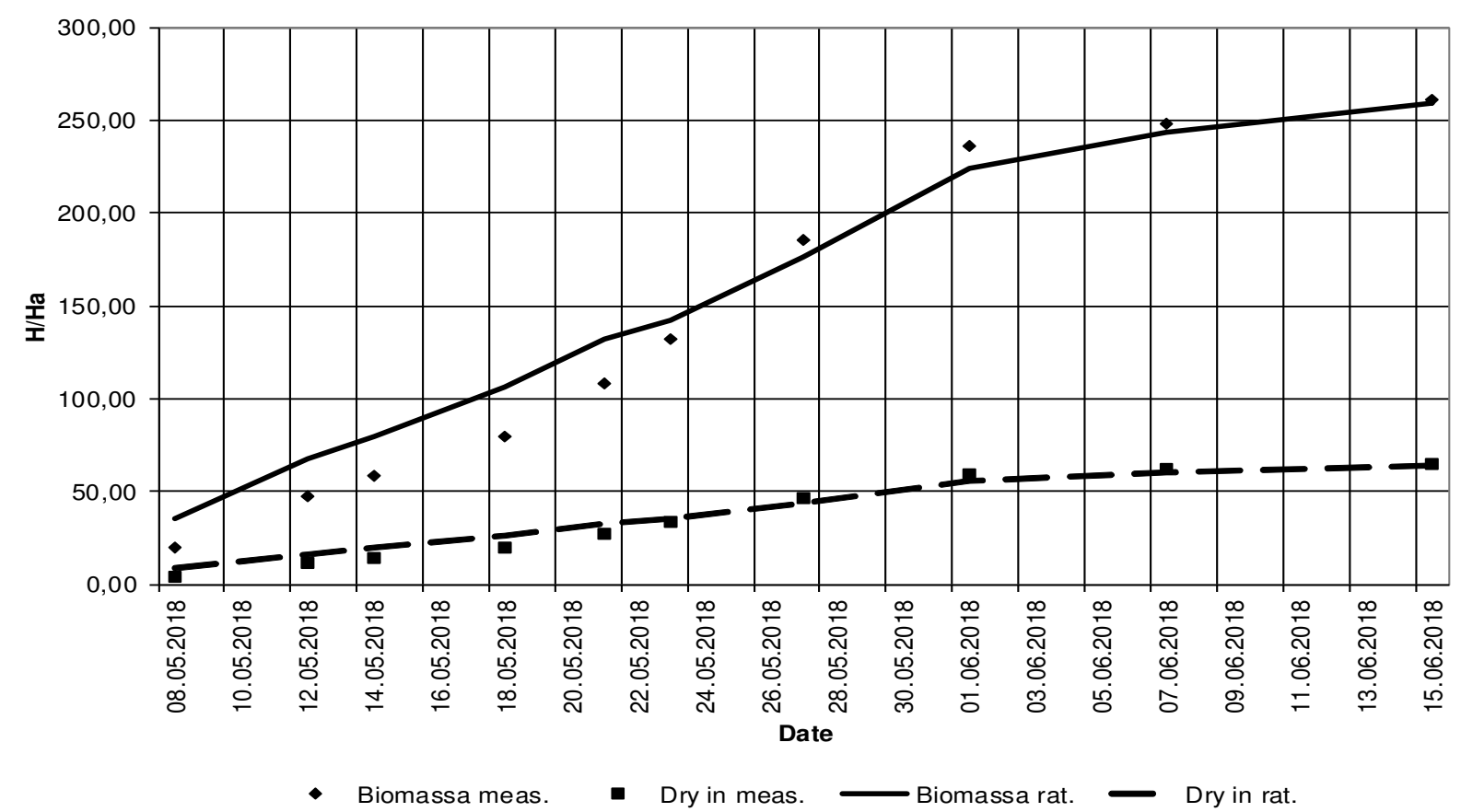

Fig. 3. Process of optimal assessment of state of sowing according to remote sensing data

The estimation algorithm (6) provides 3-5\% accuracy of estimation, which is quite enough for the development of technological effects on the crop according to the information of remote optical meters. 
All control decisions on pastures are associated with the spatial distribution of the parameters of the state of the crops and soil environment. At the same time, the algorithm (6) and all mathematical models used in it reflect only parameters averaged over the area. The question arises: what about the rest of the field or pasture?

The peculiarity of the production process model (1) is the strict Cauchy vector-matrix canonical form, intended for solving the problems of estimation and control. Moreover, the parameters of this model can be easily estimated from the information obtained as a result of an identification experiment on the test sites. However, the form of this model does not show how the spatial inhomogeneity of the parameters of the state of the phytomass over the field is taken into account. Sources of such heterogeneity are the presence of soil differences, the unevenness of the technological impact of machines and animals on grazing, as well as the influence of the relief in the agricultural landscape. Spatial heterogeneity of sowing can easily be reflected in mathematical models when using remote sensing systems of sowing, when two-dimensional electronic images are formed in the desired spectra, which reflect the state of sowing over the entire field area.

Introducing spatial variables on the horizontal plane $(\mathrm{z}, \mathrm{h})$; the model of the optical meter in the remote optical sensing system will be presented in the following form

$$
F[X(z, h)]=\left[\begin{array}{c}
p 1 e^{-p_{2}\left(X_{1}(z, h)+X_{2}(z, h)\right)} \\
p_{3} e^{-p_{4} X_{2}(z, h)}
\end{array}\right] .
$$

Similarly, the model of the parameters of the state of the phytomass can be represented, which is quite acceptable, in view of the weak redistribution of energy and substance over the area of the field

$$
\begin{gathered}
\dot{X}(t, z, h)=A X(t, z, h)+C F(t)+B u(t, z, z h)+\zeta(t, z, h), \\
t \in(O, T), X(O, z, h)=X_{0}(z, h), z \in(1, Z), h \in(1, H) \\
Y_{x}(z, y)=F[X(x, y)]+E(t, z, y) .
\end{gathered}
$$

Similarly, the model of the parameters of the state of the phytomass can be represented, which is quite acceptable, in view of the weak redistribution of energy and substance over the area of the field

$$
\begin{gathered}
\hat{X}(t, z, h)=A \hat{X}(t, z, h)+C F(t)+B X_{3}(t, z, h)+R(t) \frac{\partial F^{T}[\hat{X}(z, h)]}{\partial X} \sum^{-1}\left(Y_{x}(t, z, h)-F(\hat{X}(z, h))\right), \\
\dot{R}=D+R(t) A^{T}+A R(t)-R(t) \frac{\partial F^{T}(\hat{X})}{\partial \hat{X}} \sum^{-1} \frac{\partial F^{T}(\hat{X})}{\partial \hat{X}} R(t), \\
\hat{X}(O, x, h)=M\left[X_{0}(z, h)\right], R(0)=\operatorname{cov}\left[X_{0}\right], t \in(O, T), z \in(1, Z), h \in(1, H), \\
\Sigma=\left[\begin{array}{cc}
\sigma_{1}^{2} & \sigma_{1} \sigma_{2} \\
\sigma_{1} \sigma_{2} & \sigma_{2}^{2}
\end{array}\right] .
\end{gathered}
$$

The main feature of the canonical forms of the original model of dynamics (8) and the model of estimating the parameters of the state of crops (10) is that the modeling variable here is not a vector of state parameters with scalar components, but a vector of two-dimensional images of biomass state parameters. The source of such images is remote sensing data, which are entered into the evaluation system through a measurement model (9). This model allows two types of solutions. In the first case, the solution is carried out over all points of the field space, for which it is divided into many elementary sections, and the modeling program has nested cycles for each spatial variable. In the second case, the solution is carried out only for sufficient statistics of state parameters, which are: the mean over the field value of the vector of the state parameters of the biomass and the covariance matrix of the state parameters of the phytomass. Obviously, the first type of solution can be used to implement the management of technological operations taking into account the spatial heterogeneity 
of the state parameters, and the second one - to assess the risks of yield losses from the spatial heterogeneity of the biomass state.

In the case, when it is necessary to solve only the problem of estimating the parameters of the state of the biomass over the area of a field or pasture, an approximation approach can be used. It complements the above-mentioned variant of sufficient statistics of state parameters and consists in the fact that the average state area estimates of the state parameters are corrected by a linear corrector of the form:

$$
\Delta \hat{X}(z, h)=K \Delta Y_{x}(z, h)
$$

where $\Delta \hat{X}(z, h)$ - spatial corrective correction of the estimates for the coordinate $(z, h)$;

$Y_{x}(z, h)$ - spatial variation of the reflection parameters of the ERS system;

$K$ - corrector parameter matrix.

In this case, the estimation of the state parameters for any spatial coordinate is formed as follows

$$
\hat{X}(z, h)=\tilde{X}(z, h)+\Delta \hat{X}(z, h),
$$

where $\tilde{X}(z, h)$ - average over the area of land value of vector estimates of the parameters of the state of the phytomass.

Fig. 4 shows a fragment of the spatial distribution of estimates (12) over the land area.

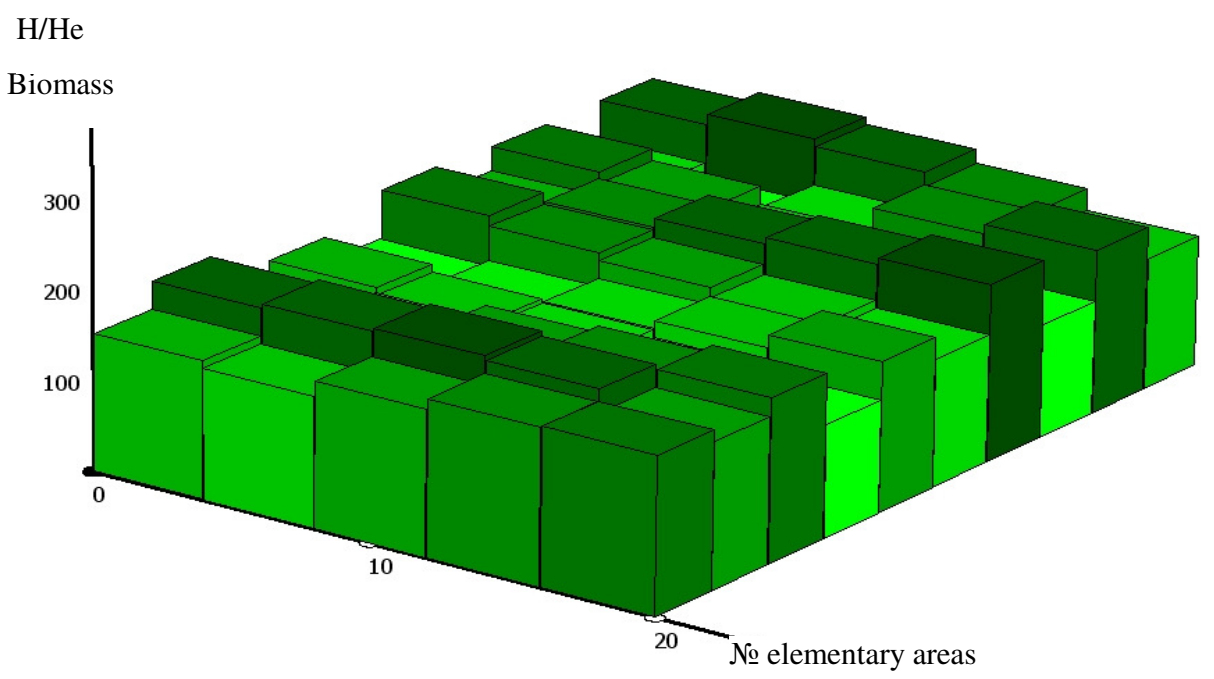

Fig. 4. Fragment of spatial distribution of estimates of total biomass of grass stand

\section{Conclusions}

1. A method is proposed for estimating the parameters of the state of the grass stands of cultivated pastures, involving the use of the Earth remote sensing (ERS) data and ground measurements on the test sites. In accordance with the methodology, the integration of remote sensing data and ground-based measurements is carried out in an optimal filtering algorithm, for implementation of which a mathematical model of the dynamics of the estimated parameters of the state of the stand and the model of optical measurements (remote sensing) are used.

2. To estimate the parameters of the models, the test sites of cultivated pastures are used, from which samples of plants and soil are taken. For the formation of the spatial distribution of estimates in mathematical models, two-dimensional variables were introduced and various approaches were proposed for constructing their estimates, using electronic remote sensing images. The assessment results can be used to make management decisions aimed at maintaining the quality and productivity of pasture grass stands. 


\section{Acknowledgements}

The work was carried out with the financial support of the Ministry of Science and Higher Education of Russia under Agreement No. 14.613.21.0081 with the Ministry of Science and Higher Education in Russia dated November 22, 2017. Unique identifier of works: RFMEFI61317X0081.

\section{References}

[1] Абатуров Б.Д. Пастбищный тип функционирования степных и пустынных экосистем (Abaturov B.D. Pasture type of functioning of steppe and desert ecosystems). Successes of modern biology, T. 126, No. 5, 2006, pp. 435-447. (In Russian).

[2] Казаков И.Е. Методы оптимизации стохастических систем (Kazakov I. Ye. Methods for optimization of stochastic systems). Moscow: Science, 1987. 348 p. (In Russian).

[3] Михайленко И.М. Основные задачи оценки состояния посевов и почвенной среды по данным космического зондирования (Mikhaylenko I.M. The main tasks of assessing the state of crops and the soil environment according to space sensing data). Ecological Systems and Devices, No. 8, 2011, pp. 17-25. (In Russian).

[4] Рачкулик В.И., Ситникова М.В. Отражающие свойства и состояние растительности (Rachkulik V.I., Sitnikova M.V. Reflective properties and state of vegetation). Leningrad: Hydrometeoizdat, 1981. 287 p. (In Russian).

[5] Harmoney K.R., Moore K.J., George I.R. et al. Determination of pasture biomass using four indirect methods. Agronomy Journal, No. 89, 1997, pp. 665-672.

[6] Jordan C.F. Derivation of leaf area index from quality of light on the forest floor, Ecology, vol. 50, 1969, pp. 663-666.

[7] Kriegler F.J., Malila W. A., Nalepka R. F., Richardson W. Preprocessing transformations and their effects on multispectral recognition, in Proceedings of the Sixth International Symposium on Remote Sensing of Environment University of Michigan, 1969, Ann Arbor. MI, pp. 97-131.

[8] Keith Watson, Rick Gatto Moisture and salinity sensor and method of use. Patent WO1992007251 A1. 30.04, 1992.

[9] Lillesand T.M., Kiefer R.W. Remote Sensing and Image Interpretation. 2nd edition, John Wiley and Sons: New York, Chichester, Brisbane, Toronto, Singapore, 1987. 721 p.

[10] Михайленко И.М., Тимошин В.Н., Малыгин В.Д. Принятие решения о дате закупки корма на основе данных дистанционного зондирования Земли и адаптируемых математических моделей (Mikhaylenko I.M., Timoshin V.N., Malygin V.D. Making decisions on the date of procurement of feed on the basis of data of remote sensing of the Earth and adaptable mathematical models). Modern problems of remote sensing of the earth from space, vol. 14, No. 2, 2017, pp. 65-79. (In Russian).

[11] Hatfield J., Gitelson A., Schepers J. et al. Walthall Application of Spectral Remote Sensing for Agronomic Decisions. Published in Agron. J., vol. 100, 2008, pp. 117-131.

[12] Михайленко И.М., Курашвили А.Е. 2008. Прогнозирование состояния травостоя в системе управления качеством кормов в молочном животноводстве (Mikhaylenko I.M., Kurashvili A.E. Prediction of the state of herbage in the system of quality management of feed in dairy farming). Vestnik RSHA, No. 2, 2008, pp. 10-13. (In Russian).

[13] Crippen R.E. Calculating the Vegetation Index Faster. Remote Sensing of Environment, vol. 34, 1990, pp. 71-73.

[14] Sanderson M.A., Rotz C.A., Fultz S.W., Rauburn E.B. Estimating forage mass with a commercial capacitance meter, rising plate meter, and pasture ruler. Agronomy Journal, No. 93, 2001, pp. 1281-1286. 